\title{
Changes in Utilization of Birth Control and PrEP During COVID-19 in the USA: A Mixed-Method Analysis
}

\author{
Rachel A. Fikslin 1,2,3 (D) Alison J. Goldberg ${ }^{1,2,3}$ - Amanda N. Gesselman ${ }^{4} \cdot$ Mora A. Reinka $^{5} \cdot$ Omaima Pervez $^{1}$. \\ Elissia T. Franklin ${ }^{6,7} \cdot$ Olivia Ahn $^{3} \cdot$ Devon M. Price ${ }^{1,3}$
}

Received: 23 December 2020 / Revised: 17 June 2021 / Accepted: 21 June 2021 / Published online: 8 November 2021

(c) The Author(s), under exclusive licence to Springer Science+Business Media, LLC, part of Springer Nature 2021

\begin{abstract}
In the USA, the COVID-19 pandemic has created challenges beyond the direct consequences of the infection. Because of shifting resources in response to need, many domains within the healthcare sector unrelated to COVID-19 have had interrupted abilities to provide care. In the current study, we focus on preventative sexual health care during the pandemic. In a sample of 511 (mean age $=27.7$ ) people, we examined quantitative data regarding continuation and discontinuation of birth control and PrEP during the pandemic, along with qualitative data illustrating the underlying reasons for participants' (dis) continuation. Results showed that most (92.5\%) of birth control users reported continuation of their birth control, with the predominant reasons reported being use for health reasons, long-acting reversible contraceptive use, access to remote healthcare services, and increased vigilance over pregnancy prevention. Conversely, around half (52.6\%) of PrEP-using participants reported already discontinuing or planning to discontinue their PrEP regimen. Temporary abstinence and concerns about accessing in-person health care were the predominant reasons for PrEP discontinuation. These results have implications for both researchers and sexual healthcare providers. Disruptions to preventative sexual health care should be considered in ongoing research about patient needs, and healthcare providers may wish to consider particular challenges faced by PrEP users concerning re-start and continuation.
\end{abstract}

Keywords PrEP · Birth control · COVID-19 · Preventative sexual health care

Rachel A. Fikslin and Alison J. Goldberg have contributed equally to this work.

\section{Devon M. Price}

dp2270@hunter.cuny.edu

1 Department of Psychology, Hunter College of the City University of New York, 695 Park Ave, New York, NY 10065, USA

2 Basic and Applied Social Psychology (BASP) PhD Program, Department of Psychology, Graduate Center of the City University of New York, New York, NY, USA

3 Hunter Alliance for Research and Translation (HART), Hunter College of the City University of New York, New York, NY, USA

4 The Kinsey Institute, Indiana University, Bloomington, IN, USA

5 Department of Psychology, Ursinus College, Collegeville, PA, USA

6 Research Her, LLC, South Holland, IL, USA

7 Silent Spring Institute, Newton, MA, USA

\section{Introduction}

COVID-19 has posed a myriad of indirect challenges for individuals' health and well-being including social isolation, job loss, and financial insecurity. In addition to these challenges, the pandemic brought new obstacles to receiving care for health concerns unrelated to COVID-19 as it began to take a toll on healthcare systems. Critical resources (e.g., respirators) were reassigned from other medical units to COVID-19 wards, the majority of non-critical medical procedures were canceled, and the ability to access routine care and care for non-COVID-19 emergencies was vastly reduced (American Hospital Association [AHA], 2020). Despite many patients seeking urgent care related to COVID-19 in March and April of 2020, hospital emergency rooms experienced a $42 \%$ drop in weekly visitors from the previous year (Ornstein, 2020), demonstrating a reduction in healthcare utilization typically needed for reasons unrelated to COVID-19. This suggests that nearly half of those with healthcare needs that would otherwise prompt them to seek critical, time-sensitive care did not do so. This shift may have been due 
to patients' assumptions that they would not receive help from an overburdened medical center, or to fear that they would expose themselves to the COVID-19 virus in the process of seeking care (Ornstein, 2020).

Taken together, these challenges may have affected access and decision making for various areas of routine health care. One area likely to have unique and substantial challenges is preventative sexual health care. Preventative sexual health care aims to prevent unintended pregnancies and sexually transmitted infections. The Centers for Disease Control and Prevention reported that in the USA, $12.6 \%$ of 72.2 million cisgender women aged $15-49$ years were prescribed the hormonal birth control pill between 2015 and 2017. This means an estimated 9 million women could have needed these services during the 2020 COVID-19 pandemic (Centers for Disease Control \& Prevention, 2019). Additionally, approximately 225,000 Americans were actively taking preexposure prophylaxis (PrEP) in the years prior to the pandemic to protect themselves against HIV (Pebody, 2018). Thus, a sizable portion of the American population may have experienced disruptions to these important forms of preventative sexual health care. Although birth control and PrEP are only two forms of potential sexual healthcare needs that could arise during the COVID-19 pandemic, the consequences of discontinuing birth control or PrEP can be long-lasting and life-altering. In the current study, we investigate the discontinuation of birth control and PrEP, including reported reasons for such discontinuation as well as the predictors of needing access to these medications during the pandemic.

\section{Potential Implications of COVID-19 for Birth Control Use}

In the USA, birth control is widely used by individuals assigned female at birth (Kanj et al., 2019; Mosher \& Jones, 2010). More than $99 \%$ of cisgender women in the USA aged 15-44 who have ever had sexual intercourse have used at least one contraceptive method (Mosher \& Jones, 2010). Among contraceptive users, $25.3 \%$ use oral contraceptives, $21.8 \%$ rely on tubal sterilization, $11.8 \%$ use intrauterine devices (IUDs), 3.9\% use injectables, $2.6 \%$ use implants, and $2.4 \%$ use vaginal rings (Guttmacher, 2020). In the current study, these methods are collectively referred to as "birth control." Although condoms are also a commonly used contraceptive method, the present investigation focuses on birth control that requires engagement with the healthcare system and is thus more likely to be impacted by COVID-19-related disruptions.

While oral contraceptives and tubal sterilization have been the two most common birth control methods since 1982 (Guttmacher, 2020), the use of long-acting reversible contraceptives (LARCs) such as IUDs and implants has become increasingly more common, rising from $6 \%$ of contraceptive users in 2008 to 14\% in 2014 (Kavanaugh \& Jerman, 2018). In addition to pregnancy prevention, birth control is prescribed to treat numerous reproductive health concerns such as endometriosis (Grandi et al., 2019), polycystic ovary syndrome (Mendoza et al., 2014), premenstrual syndrome, and premenstrual dysphoric disorder (Lete \& Lapuente, 2016).

Despite the prevalence of birth control use, barriers to access still exist. Nearly all birth control methods require a prescription, which presents an obstacle for those who do not have insurance, access to a doctor or clinic, time to devote to an appointment, and/ or the financial resources to pay for an appointment (Zuniga et al., 2019). Transportation barriers and a lack of nearby pharmacies may also impede birth control access (Lin \& Lee, 2015). While online telemedicine platforms are a viable alternative, they differ in the birth control methods they provide, and the age-groups, insurance providers, and geographic locations they serve (Zuniga et al., 2019).

These existing barriers were likely exacerbated by the onset of the COVID-19 pandemic through increased difficulty accessing non-critical medical care (AHA, American Hospital Association, 2020), loss of income, and loss of employer-based health insurance (Barry et al., 2020). While individuals with previously inserted LARCs were likely less affected by COVID-19-related interruptions in care, those whose devices were expiring and those seeking a new prescription of continuing birth control pill use may have faced increasingly steep obstacles to accessing sexual health services. These barriers may have also affected those seeking other forms of preventative sexual health care, such as PrEP.

\section{Potential Implications of COVID-19 for PrEP Use}

PrEP is an effective biomedical HIV prevention strategy that has been increasingly utilized since it was approved by the FDA in 2012 (Food \& Drug Administration [FDA], 2014). Despite the increasing availability of PrEP, many barriers limit PrEP use, particularly for marginalized communities. Commonly cited barriers to PrEP use include logistical barriers such as cost and health insurance coverage (Patel et al., 2017) as well as sociocultural barriers such as stigma associated with PrEP use (e.g., Dubov et al., 2018; Golub et al., 2019). Even when individuals overcome barriers to PrEP uptake, they may face challenges to continued PrEP adherence. For example, due to PrEP clinical guidelines that recommend quarterly STI/HIV testing (Centers for Disease Control \& Prevention, 2017), PrEP use can require frequent interaction with the healthcare system and regular blood draws. While these protocols were determined with the goal of preventing medical complications, these monitoring requirements can serve as gatekeepers, limiting PrEP use to those who can regularly access and attend health care (Siegler et al., 2019).

Because PrEP is a biomedical HIV prevention medication, many understand PrEP as being relevant solely for individuals who engage in health behaviors that put one at increased risk for HIV, including having multiple sexual partners, intravenous drug use, and/or engaging in condomless penetrative sex, with 
a particular focus on anal sex. The largest proportion of PrEP users in the USA are men who have sex with men (MSM); this community also disproportionately holds the burden of HIV prevalence (Elion et al., 2019). Beyond this focus on epidemiological risk, many use PrEP for additional benefits beyond HIV prevention such as personal psychological benefits (Allen et al., 2020; Price, English, \& Golub, 2020; Whitfield et al., 2019) and reduced anxiety in the context of HIV serodiscordant partnerships (Carlo Hojilla et al., 2016). There are multiple ways that individuals take HIV-prevention medications, including taking post-exposure prophylaxis (PEP) after a potential exposure and taking event-driven PrEP planned around a potential exposure. While most PrEP users take the pill daily, event-driven PrEP involves taking two pills in the $24 \mathrm{~h}$ before an anticipated potential HIV exposure (e.g., sexual encounter), and then, one pill each day for two days after the potential exposure (often called 2-1-1 PrEP). This method is often preferred when individuals are able to anticipate sexual encounters (Reyniers et al., 2018), which may be more common during COVID-19 when many may be making more intentional decisions about intimate contact. Ultimately, PrEP use decisions may be reliant on healthcare access, sexual behavior, and psychological factors, all of which have likely been impacted by COVID-19.

To date, little is known about the ways that the ongoing COVID-19 pandemic has influenced PrEP use. What we do know, however, is that many individuals are continuing to engage in sexual behavior that could transmit HIV (Lehmiller et al., 2021; Stephenson et al., 2020) illustrating the continuing need for access to PrEP. Limited existing research on PrEP and COVID-19 suggests that the majority of PrEP users are maintaining PrEP use (Fernandes et al., 2020; Pampati et al., 2020). Ultimately, the existing studies about HIV risk behavior, PrEP, and COVID-19 suggest that understanding PrEP use patterns during the pandemic is crucial for understanding the health and well-being of PrEP users.

COVID-19 has likely interrupted preventative sexual health care for both birth control and PrEP in some similar ways; however, there are key differences to note. While HIV risk is assumed to increase with the number of sexual partners (Centers for Disease Control \& Prevention, 2017), pregnancy risk is conveyed by each instance of intercourse, irrespective of the number of unique partners. A couple who does not use any contraceptive method for vaginal intercourse has an $85 \%$ chance of becoming pregnant within one year (Guttmacher, 2020). Therefore, stay-at-home orders and quarantine procedures impact pregnancy risk and HIV risk - and birth control and PrEP use, respectively — differently. Further, stigmatization and required interaction with the healthcare system differ for these two preventative medications. Exploring birth control and PrEP side by side provides a case study for understanding factors that impact one's ability and decision to continue or discontinue preventative sexual healthcare services during the COVID-19 pandemic.

\section{Present Study}

In the present exploratory study, we examined changes to the utilization of birth control and PrEP during the onset of the COVID19 pandemic in the USA, between April and June 2020. Specifically, the present study aimed to address the following questions: (1) How common was the discontinuation of birth control or PrEP during the first months of the COVID-19 pandemic in the USA? (2) What was the relationship between sexual behavior and rates of (dis)continuation? (3) What reasons did people selfreport for their birth control or PrEP (dis)continuation?

\section{Method}

\section{Participants}

Participants were 235 men, 217 women, 44 non-binary individuals, and 8 who identified as something else or skipped the gender item $(N=511)$. Nine percent of the full sample identified as transgender $(n=48)$. Mean age was 27.73 years. The sample was majority white (72\%) with the next largest groups identifying as Black/African American (12\%) and Multiracial (11\%). Twentyone percent of the sample was Latinx. Regarding sexual orientation, $40 \%$ identified as heterosexual, $18 \%$ identified as bisexual, $17 \%$ identified as gay or lesbian, $12 \%$ identified as queer, $7 \%$ identified as pansexual, $3 \%$ identified as asexual, $2 \%$ reported another identity, and $3 \%$ said they were not sure. Full participant demographics are presented in Table 1.

At the time of data collection, April through June 2020, the USA was experiencing the first major wave of the COVID-19 pandemic. Many areas of the country had instituted policies aimed at limiting COVID-19 transmission. Via a checklist item, all participants indicated that nonessential travel has been banned or discouraged in their local area, and $91.4 \%$ indicated that large public gatherings had been banned or were limited in size; $80.8 \%$ reported that nonessential businesses were closed, including bars, restaurants, gyms, and other social gathering spots. While we did not ask specifically about whether doctor's offices were open, these statistics indicate that most participants were experiencing limitations on their ability to travel, gather, and access public spaces.

\section{Procedure}

Participants were recruited via social media posts advertising the study and via an email list from prior studies conducted by the Hunter Alliance for Research and Translation (HART) on sexual health containing participants who had consented to be contacted again for future research purposes. Eligibility criteria were being 18 years or older, being fluent in English, and living in the USA. 
Table 1 Participant Demographics $(\mathrm{N}=511)$

\begin{tabular}{|c|c|c|}
\hline & $n$ or $M$ & $\%$ or $S D$ \\
\hline Age & 27.73 & 9.13 \\
\hline \multicolumn{3}{|l|}{ Race $^{\mathrm{a}}$} \\
\hline White & 369 & $72.21 \%$ \\
\hline Native American or Alaska Native & 8 & $1.57 \%$ \\
\hline East Asian & 24 & $4.70 \%$ \\
\hline West Asian & 6 & $1.17 \%$ \\
\hline Black/African American & 59 & $11.55 \%$ \\
\hline Native Hawaiian or other Pacific Islander & 6 & $1.17 \%$ \\
\hline Multiracial & 57 & $11.15 \%$ \\
\hline Other & 28 & $5.48 \%$ \\
\hline Latinx $(n=488)$ & 109 & $22.34 \%$ \\
\hline \multicolumn{3}{|l|}{ Income $(n=457)$} \\
\hline$<\$ 20,000$ & 54 & $11.82 \%$ \\
\hline$\$ 20,000-\$ 55,000$ & 101 & $22.10 \%$ \\
\hline$\$ 55,000-\$ 100,000$ & 134 & $29.32 \%$ \\
\hline$\$ 100,000+$ & 119 & $26.04 \%$ \\
\hline Don't know/prefer not to answer & 49 & $10.72 \%$ \\
\hline \multicolumn{3}{|l|}{ Education $(n=459)$} \\
\hline Less than BA & 169 & $36.82 \%$ \\
\hline BA & 129 & $28.10 \%$ \\
\hline More than BA & 156 & $33.99 \%$ \\
\hline Other & 5 & $1.09 \%$ \\
\hline \multicolumn{3}{|l|}{ Gender identity $(n=504)$} \\
\hline Man & 235 & $46.63 \%$ \\
\hline Woman & 217 & $43.06 \%$ \\
\hline Non-binary & 44 & $8.73 \%$ \\
\hline Agender & 3 & $0.60 \%$ \\
\hline Do not know & 3 & $0.60 \%$ \\
\hline Another gender identity not listed & 1 & $0.20 \%$ \\
\hline Choose not to answer & 1 & $0.20 \%$ \\
\hline Transgender $(n=508)$ & 48 & $9.45 \%$ \\
\hline \multicolumn{3}{|l|}{ Sexual orientation $(n=510)$} \\
\hline Asexual & 13 & $2.55 \%$ \\
\hline Bisexual & 91 & $17.84 \%$ \\
\hline Gay or lesbian & 84 & $16.47 \%$ \\
\hline Heterosexual & 202 & $39.61 \%$ \\
\hline Pansexual & 35 & $6.86 \%$ \\
\hline Queer & 60 & $11.76 \%$ \\
\hline I'm not sure & 14 & $2.75 \%$ \\
\hline Another identity not listed & 11 & $2.16 \%$ \\
\hline \multicolumn{3}{|l|}{ Relationship status $(n=510)$} \\
\hline Single & 248 & $48.63 \%$ \\
\hline One or more serious relationships & 251 & $49.22 \%$ \\
\hline Other & 11 & $2.16 \%$ \\
\hline \multicolumn{3}{|l|}{ Region $(n=498)$} \\
\hline West & 115 & $23.09 \%$ \\
\hline Midwest & 58 & $11.65 \%$ \\
\hline South & 182 & $36.55 \%$ \\
\hline Northeast & 140 & $28.11 \%$ \\
\hline Pacific & 4 & $0.80 \%$ \\
\hline
\end{tabular}

${ }^{\text {a }}$ Participants were able to select all of the race and ethnicity categories presented. The total percentages equal greater than $100 \%$ because many participants selected more than one category
The survey was conducted fully online using the RedCap platform and was self-paced. Participants completed the surveys between April and June of 2020, which was 1-3 months after the World Health Organization declared COVID-19 a global pandemic in March 2020 (Chappell, 2020). In addition to providing demographic information, participants responded to a variety of measures regarding their sexual healthcare utilization and COVID-19 prevention behaviors during the onset of the COVID-19 pandemic. Participants could skip any items they did not wish to answer, which is reflected in fluctuating sample sizes in the analyses. Compensation was given in the form of 17 raffled virtual gift cards for \$40 USD.

\section{Measures}

These data were taken from a larger survey on multifaceted health outcomes during the COVID-19 pandemic in the USA. Here we only include measures relevant to the current study. Note that the survey explicitly stated for participants that the COVID-19 pandemic began in the USA around March 2020.

\section{Birth Control Use and Continuation}

Participants reported whether or not they were using birth control by responding to the question, "Are you currently using contraception/birth control methods other than condoms (i.e., birth control pills, IUD, etc.)?" If participants indicated birth control use, they were asked whether they were using an IUD, hormonal pills, injection, or implant. Current users were then asked, "You indicated you were taking contraception/birth control. Do you have plans to discontinue your prescription during lockdown?" to assess (dis)continuation. Individuals who indicated plans for stopping birth control use were categorized as birth control discontinuers. Individuals who did not report intentions to stop using birth control were categorized as birth control continuers. Note that we did not define "lockdown" for participants. However, "lockdown" was common terminology around the world at the time of data collection, encompassing stay-at-home orders, nonessential businesses closing, quarantining, and curfews (Perra, 2021).

\section{PrEP Use and Continuation}

Participants were asked about PrEP use using the question, "Are you currently using PrEP for biomedical prevention against HIV?" with dichotomous yes/no response options. Additionally, to capture individuals who had already stopped PrEP prior to the survey, all participants were asked, "Were you using PrEP before the pandemic started but stopped due to lockdown orders?" Participants who indicated that they were currently using PrEP were asked, "You indicated you were taking PrEP. Do you have plans to discontinue your 
prescription during lockdown?" Individuals who either indicated stopping PrEP use due to the pandemic or indicated plans to discontinue during lockdown were categorized as PrEP discontinuers. Individuals currently taking PrEP who did not have plans to discontinue during lockdown were categorized as PrEP continuers.

\section{Reasons for (Dis)continuation}

Individuals who indicated using PrEP or birth control were asked open-ended questions about whether their approaches had changed. The questions read, "Since the beginning of the COVID-19 Coronavirus pandemic, have you changed your approach to contraceptives or birth control (pre-exposure prophylaxis (PrEP for HIV prevention))?".

\section{Sexual Behavior During the Pandemic}

Participants responded to dichotomous yes/no questions about their sexual activity during and before the pandemic. They reported whether they had engaged in any partnered sexual activity since the beginning of the COVID-19 pandemic in the USA (since March 2020), as well as within the last two weeks. They also reported intentions to engage in partnered sexual activity in the next two weeks and whether they were currently having sex with someone outside their household/lockdown pod. Additionally, participants reported the number of partners with whom they engaged in sexual activity in the last three months, the number of different types of sex acts in the past 30 days (e.g., oral sex, anal sex, vaginal sex), and the percentage of time they used condoms during intercourse in the last 30 days (sliding scale from $0 \%$ to $100 \%)$.

\section{Likelihood of Needing Sexual Healthcare Services}

Participants reported their likelihood of needing access to different sexual healthcare services (i.e., contraceptives, morning after pill/emergency contraception, and PrEP/PEP) during lockdown on a 7-pt Likert scale from (1) very unlikely to (7) very likely.

\section{Sample and Quantitative Analysis}

There were 744 individuals who consented to participate in the survey. Of those who started the survey, 233 did not complete the sections on birth control or PrEP, leaving a final sample of 511. Because of the small number of birth control discontinuers $(n=10)$ and a relatively small number of PrEP users $(n=57)$, we did not have adequate power to conduct inferential statistics to test whether demographic or behavioral factors predicted birth control or PrEP continuation. However, the consequences of discontinued preventative health care are wide-ranging and potentially quite serious. As such, we proceed by presenting demographic trends: comparisons between continuers and discontinuers, and between the full sample and PrEP/birth control users. All analyses were prepared using the Statistical Package for the Social Sciences (SPSS 26.0).

\section{Qualitative Analysis}

We analyzed the open-text responses regarding changes participants have made to their PrEP or birth control use following a thematic analysis approach (Braun \& Clarke, 2006), with themes being data-driven rather than theoretically driven. Three members of the research team developed a codebook of reasons for PrEP continuation and discontinuation, and a codebook of reasons for birth control continuation and discontinuation. The two co-first authors coded the responses independently and discussed discrepancies to reach intercoder agreement. The main themes from the coding are presented below.

\section{Results}

\section{Quantitative Analysis}

\section{Birth Control Use and Discontinuation}

Demographics and sexual behavior of birth control users, continuers, and discontinuers are presented in Table 2. About onequarter of the sample $(n=136 ; 26.7 \%)$ were birth control users, meaning they responded "yes" to the question, "Are you currently using contraception/birth control methods other than condoms (i.e., birth control pills, IUD, etc.)?' Among birth control users, the most common method of contraception was an IUD (44.1\%), followed by hormonal pills (41.9\%) and implants (8.8\%). Two participants (1.5\%) indicated using both IUDs and hormonal pills, and one participant $(0.7 \%)$ reported using injections. Four participants (2.9\%) indicated current birth control use but did not respond to the question about specific type. Two of these participants later indicated the use of permanent birth control methods (tubal sterilization and vasectomy), while the other two declined to provide additional information.

The individuals using birth control had a similar demographic breakdown to the overall sample. A higher percentage of birth control users had a college degree or higher (44.6\%), were heterosexual (44.4\%), and were in a serious relationship (76.3\%), relative to the full sample.

Compared to nonusers, descriptive trends suggest that birth control users differed in their sexual behavior, with birth control users more sexually active than nonusers (see Table 3 for full sample sexual behavior). More birth control users reported 
Table 2 Descriptive characteristics of birth control users, continuers, and discontinuers

\begin{tabular}{|c|c|c|c|c|c|c|}
\hline & \multicolumn{2}{|c|}{$\begin{array}{l}\text { Birth control User } \\
(n=136)\end{array}$} & \multicolumn{2}{|c|}{ Continuer $(n=124)$} & \multicolumn{2}{|c|}{$\begin{array}{l}\text { Discontinuer } \\
(n=10)\end{array}$} \\
\hline & $n$ or $M$ & $\%$ or $S D$ & $n$ or $M$ & $\%$ or $S D$ & $n$ or $M$ & $\%$ or $S D$ \\
\hline Age & 27.47 & 6.55 & 27.72 & 6.69 & 25.3 & 4.06 \\
\hline \multicolumn{7}{|l|}{ Race $^{\mathrm{a}}$} \\
\hline White & 107 & 78.68 & 100 & 80.65 & 6 & 60.00 \\
\hline Native American or Alaska Native & 4 & 2.94 & 3 & 2.42 & 1 & 10.00 \\
\hline East Asian & 6 & 4.41 & 4 & 3.23 & 2 & 20.00 \\
\hline West Asian & 2 & 1.47 & 2 & 1.61 & 0 & 0.00 \\
\hline Black/African-American & 13 & 9.56 & 10 & 8.06 & 2 & 20.00 \\
\hline Native Hawaiian or other Pacific Islander & 1 & 0.74 & 1 & 0.81 & 0 & 0.00 \\
\hline Multiracial & 13 & 9.56 & 12 & 9.68 & 1 & 10.00 \\
\hline Other & 4 & 2.94 & 4 & 3.23 & 0 & 0.00 \\
\hline Latinx $(n=130)$ & 28 & 21.54 & 25 & 21.19 & 2 & 20.00 \\
\hline \multicolumn{7}{|l|}{ Income $(n=130)$} \\
\hline$<\$ 20,000$ & 13 & 10.00 & 13 & 10.92 & 0 & 0.00 \\
\hline$\$ 20,000-\$ 55,000$ & 24 & 18.46 & 20 & 16.81 & 4 & 40.00 \\
\hline$\$ 55,000-\$ 100,000$ & 44 & 33.85 & 42 & 35.29 & 2 & 20.00 \\
\hline$\$ 100,000+$ & 39 & 30.00 & 38 & 31.93 & 1 & 10.00 \\
\hline Don't know/prefer not to answer & 10 & 7.69 & 6 & 5.04 & 3 & 30.00 \\
\hline \multicolumn{7}{|l|}{ Education $(n=130)$} \\
\hline Less than BA & 30 & 23.08 & 28 & 23.53 & 1 & 10.00 \\
\hline BA & 41 & 31.54 & 36 & 30.25 & 5 & 50.00 \\
\hline More than BA & 58 & 44.62 & 54 & 45.38 & 4 & 40.00 \\
\hline Other & 1 & 0.77 & 1 & 0.84 & 0 & 0.00 \\
\hline \multicolumn{7}{|l|}{ Gender identity } \\
\hline Man & 23 & 16.91 & 23 & 18.55 & 0 & 0.00 \\
\hline Woman & 97 & 71.32 & 85 & 68.55 & 10 & 100.00 \\
\hline Non-binary & 13 & 9.56 & 13 & 10.48 & 0 & 0.00 \\
\hline Agender & 3 & 2.21 & 3 & 2.42 & 0 & 0.00 \\
\hline Transgender & 13 & 9.56 & 13 & 10.48 & 0 & 0.00 \\
\hline \multicolumn{7}{|l|}{ Sexual orientation $(n=135)$} \\
\hline Asexual & 3 & 2.22 & 2 & 1.61 & 0 & 0.00 \\
\hline Bisexual & 34 & 25.19 & 32 & 25.81 & 1 & 11.11 \\
\hline Gay or lesbian & 4 & 2.96 & 4 & 3.23 & 0 & 0.00 \\
\hline Heterosexual & 60 & 44.44 & 56 & 45.16 & 4 & 44.44 \\
\hline Pansexual & 12 & 8.89 & 10 & 8.06 & 2 & 22.22 \\
\hline Queer & 17 & 12.59 & 16 & 12.90 & 1 & 11.11 \\
\hline I'm notsure & 3 & 2.22 & 2 & 1.61 & 1 & 11.11 \\
\hline Another identity not listed & 2 & 1.48 & 2 & 1.61 & 0 & 0.00 \\
\hline \multicolumn{7}{|l|}{ Relationship status $(n=135)$} \\
\hline Single & 32 & 23.70 & 26 & 20.97 & 5 & 50.00 \\
\hline One or more serious relationships & 103 & 76.30 & 97 & 78.23 & 5 & 50.00 \\
\hline Other & 0 & 0.00 & & 0.00 & & 0.00 \\
\hline \multicolumn{7}{|l|}{ Region $(n=135)$} \\
\hline West & 35 & 25.93 & 33 & 26.61 & 1 & 11.11 \\
\hline Midwest & 16 & 11.85 & 15 & 12.10 & 1 & 11.11 \\
\hline South & 48 & 35.56 & 42 & 33.87 & 5 & 55.56 \\
\hline Northeast & 36 & 26.67 & 34 & 27.42 & 2 & 22.22 \\
\hline Pacific & 0 & 0.00 & & 0.00 & & 0.00 \\
\hline
\end{tabular}


Table 2 (continued)

\begin{tabular}{|c|c|c|c|c|c|c|}
\hline & \multicolumn{2}{|c|}{$\begin{array}{l}\text { Birth control User } \\
(n=136)\end{array}$} & \multicolumn{2}{|c|}{ Continuer $(n=124)$} & \multicolumn{2}{|c|}{$\begin{array}{l}\text { Discontinuer } \\
(n=10)\end{array}$} \\
\hline & $n$ or $M$ & $\%$ or $S D$ & $n$ or $M$ & $\%$ or $S D$ & $n$ or $M$ & $\%$ or $S D$ \\
\hline \multicolumn{7}{|l|}{ Sexual behavior } \\
\hline Currently having sex with anyone outside of household/isolation pod & 17 & 12.50 & 16 & $12.90 \%$ & 1 & $10.00 \%$ \\
\hline Oral sex in the past 12 months & 121 & $88.97 \%$ & 112 & $90.32 \%$ & 9 & $90.00 \%$ \\
\hline Penetrative intercourse (either anal or vaginal) in the last 12 months & 122 & $89.71 \%$ & 113 & $91.13 \%$ & 9 & $90.00 \%$ \\
\hline Engaged in any partnered activity since the beginning of the pandemic & 93 & $69.40 \%$ & 87 & $70.73 \%$ & 6 & $60.00 \%$ \\
\hline Engaged in any partnered activity in the past two weeks & 79 & $58.96 \%$ & 74 & $60.16 \%$ & 5 & $50.00 \%$ \\
\hline Planning on engaging in partnered sexual activity in the next two weeks & 84 & $62.69 \%$ & 78 & $63.41 \%$ & 6 & $60.00 \%$ \\
\hline Number of sex partners last 3 months & 1.21 & 1.06 & 1.22 & 1.09 & 1 & 0.54 \\
\hline Number oftimes gave oral sex in past 30 days & 4.39 & 5.37 & 4.31 & 5.3 & 5.44 & 6.41 \\
\hline Number of times received oral sex in past 30 days & 3.89 & 7.19 & 3.76 & 7.17 & 5.44 & 7.7 \\
\hline Number of times had vaginal sex in past 30 days & 6.74 & 8.14 & 6.81 & 8.29 & 5.89 & 6.39 \\
\hline Number of times had anal sex in past 30 days & 0.50 & 1.47 & 0.54 & 1.53 & 0 & 0 \\
\hline Percentage of time used a condom during intercourse in past 30 days & 16.11 & 33.51 & 16.73 & 34.26 & 5.17 & 12.17 \\
\hline Likelihood of needing access to PrEP/PEP during lockdown ${ }^{\text {b }}$ & 1.37 & 1.27 & 1.41 & 1.32 & 1 & 0 \\
\hline Likelihood of needing access to contraceptives during lockdown ${ }^{\mathrm{b}}$ & 3.51 & 2.78 & 3.58 & 2.79 & 3 & 2.83 \\
\hline $\begin{array}{l}\text { Likelihood of needing access to morning after pill/emergency contracep- } \\
\text { tion during lockdown }{ }^{\text {b }}\end{array}$ & 1.56 & 1.36 & 1.59 & 1.39 & 1.3 & 0.95 \\
\hline
\end{tabular}

${ }^{\text {a}}$ Participants were able to select all of the race and ethnicity categories presented. The total percentages equal greater than $100 \%$ because many participants selected more than one category. ${ }^{\mathrm{b}}$ Likelihood of needing sexual healthcare services rated on a 7 -point Likert scale $(1=$ very unlikely, $7=$ very likely)

having penetrative intercourse in the last 12 months $(n=121$; $88.9 \%$ ), compared to individuals who were not using birth control $(n=213 ; 57.6 \%)$. Birth control users were more likely to have engaged in sexual activities in the past two weeks and were more likely to report that they were planning on engaging in partnered sexual activity in the next two weeks. Birth control users, however, were no more likely to report having sex with anyone outside their household/lockdown pod than nonusers, possibly reflecting that a substantial proportion of birth control users $(n=68 ; 50.0 \%)$ lived with a relationship partner.

Of birth control users, only 10 people $(7.5 \%)$ indicated plans to discontinue their birth control prescription during the lockdown. Thus, the majority of birth control users were continuers $(n=124,92.5 \%)$, and we were not able to make inferential statistical demographic and behavioral comparisons between birth control continuers and discontinuers. A substantial portion of birth control users reported using long-acting reversible contraceptives (LARC) - with $47.0 \%$ using an IUD $(n=62)$ and $9.1 \%$ using an implant device $(n=12)$-rendering a large amount of the sample unlikely to be discontinuing during the pandemic. Remaining birth control users were either using hormonal pills $(n=57 ; 43.2 \%)$ or injection $(n=1 ; 0.8 \%)$.

\section{PrEP Use and Discontinuation}

Demographics and sexual behavior of the PrEP users, PrEP continuers, and PrEP discontinuers are found in Table 4, along with sexual behavior information. Fifty-seven (11.2\%) participants were PrEP users (i.e., either on PrEP at the time of the survey or had recently stopped due to COVID-19). The individuals taking PrEP had a similar demographic breakdown to the overall sample. There were some differences, however, with a higher percentage of PrEP users having higher education and higher income than those in the sample who were not PrEP users. Most individuals on PrEP identified with a sexual minority identity $(n=54 ; 94.7 \%)$.

Compared to nonusers, descriptive trends suggest that PrEP users engaged in more sexual behavior, which is consistent with PrEP often being recommended to those with high levels of epidemiological risk for HIV (Centers for Disease Control \& Prevention, 2017). About half of PrEP users $(n=27 ; 47.3 \%)$ planned to continue their PrEP use during the pandemic (PrEP continuers) and the other half $(n=30 ; 52.6 \%)$ had either discontinued PrEP due to the pandemic or had plans to discontinue due to the pandemic (PrEP discontinuers). Demographic patterns of continuers were similar to discontinuers.

There were some differences between PrEP continuers and PrEP discontinuers in sexual behavior, with PrEP continuers reporting more sexual activity on a variety of measures. Despite reporting similar rates of oral sex and penetrative intercourse in the past 12 months, PrEP continuers reported higher sexual behavior at the time of the pandemic. PrEP continuers were more likely to report engaging in partnered activity since the beginning of the COVID-19 pandemic $(n=21,77.8 \%)$ compared to 
Table 3 Full sample sexual behavior

\begin{tabular}{|c|c|c|}
\hline & $n$ or $M$ & $\%$ or $S D$ \\
\hline \multicolumn{3}{|l|}{ Currently having sex with anyone outside of household/isolation pod } \\
\hline Yes & 64 & 12.52 \\
\hline No & 447 & 87.48 \\
\hline \multicolumn{3}{|l|}{ Oral sex in the past 12 months } \\
\hline Yes & 377 & 73.78 \\
\hline No & 134 & 26.22 \\
\hline \multicolumn{3}{|l|}{ Penetrative intercourse (either anal or vaginal) in the last 12 months $(n=510)$} \\
\hline Yes & 340 & 66.67 \\
\hline No & 170 & 33.33 \\
\hline \multicolumn{3}{|l|}{ Engaged in any partnered activity since the beginning of the pandemic $(n=502)$} \\
\hline Yes & 254 & 50.60 \\
\hline No & 248 & 49.40 \\
\hline \multicolumn{3}{|l|}{ Engaged in any partnered activity in the past two weeks $(n=501)$} \\
\hline Yes & 187 & 37.33 \\
\hline No & 314 & 62.67 \\
\hline \multicolumn{3}{|l|}{ Planning on engaging in partnered sexual activity in the next two weeks $(n=510)$} \\
\hline Yes & 212 & 42.40 \\
\hline No & 288 & 57.60 \\
\hline Number of sex partners last 3 months $(n=379)$ & 1.67 & 2.78 \\
\hline Number of times gave oral sex in past 30 days $(n=370)$ & 3.12 & 4.97 \\
\hline Number of times received oral sex in past 30 days $(n=372)$ & 2.98 & 6.04 \\
\hline Number of times had vaginal sex in past 30 days $(n=334)$ & 4.26 & 7.36 \\
\hline Number of times had anal sex in past 30 days $(n=332)$ & 1.06 & 3.61 \\
\hline Percentage of time used a condom during intercourse (vaginal or anal) in past 30 days $(0-100 \%)(n=289)$ & 23.60 & 39.10 \\
\hline Likelihood of needing access to PrEP/PEP during lockdown $(n=492)^{\mathrm{a}}$ & 1.59 & 1.56 \\
\hline Likelihood of needing access to contraceptives during lockdown $(n=490)^{\mathrm{a}}$ & 2.20 & 2.14 \\
\hline Likelihood of needing access to morning after pill/emergency contraception during lockdown $(n=488)^{a}$ & 1.40 & 1.05 \\
\hline
\end{tabular}

${ }^{\mathrm{a}}$ Likelihood of needing sexual healthcare services rated on a 7 -point Likert scale $(1=$ very unlikely, $7=$ very likely $)$

PrEP discontinuers $(n=16 ; 53.3 \%)$. Additionally, about half of the PrEP continuers $(n=14 ; 51.9 \%)$ reported currently having sex with someone outside of their household/lockdown pod compared to a small number of PrEP discontinuers $(n=3 ; 10.0 \%)$. A higher percentage of PrEP continuers reported having sex in the past two weeks $(n=18 ; 66.7 \%)$ compared to PrEP discontinuers $(n=9 ; 30.0 \%)$ and a higher percentage of PrEP continuers reported planning to engage in partnered sexual activity in the next two weeks $(n=19 ; 70.4 \%)$ compared to PrEP discontinuers $(n=10 ; 33.3 \%)$. In addition to examining dichotomous variables describing whether or not participants engaged in sexual behavior, we asked about the frequencies of certain sexual behaviors. Comparing the means of PrEP continuers and PrEP discontinuers on sexual behavior frequency variables revealed similar trends with PrEP continuers engaging in higher numbers of sex acts and reporting a higher number of sexual partners (see Table 4). The percentage of condom use during intercourse in the past 30 days was approximately the same with PrEP continuers using condoms $10.0 \%$ of the time on average $(S D=24.9)$ and PrEP discontinuers using condoms $8.1 \%$ of the time on average
( $S D=17.6)$. Consistent with PrEP use decisions, PrEP continuers reported a higher likelihood of needing access to PrEP/PEP during lockdown on a 7-point Likert scale (PrEP continuers $M=6.04, S D=1.64$; PrEP discontinuers $M=3.48, S D=2.46$ ).

\section{Qualitative Analysis}

\section{What Reasons Do People Self-Report for Their Birth Control (Dis)continuation?}

Of the 136 birth control users who were asked to provide qualitative descriptions of their birth control use or discontinuation during the pandemic, $79.4 \%(n=108)$ responded. Those who responded were not demographically different from those who skipped the question. Eighty-one percent $(n=88)$ of these respondents reported that their birth control practices had not changed. There were five major themes related to birth control use: no or low pregnancy risk, birth control used for health reasons other than pregnancy prevention, LARC use, access to 
Table 4 Descriptive characteristics of PrEP users, continuers, and discontinuers

\begin{tabular}{|c|c|c|c|c|c|c|}
\hline & \multicolumn{2}{|c|}{ PrEP user $(n=57)$} & \multicolumn{2}{|c|}{ Continuer $(n=27)$} & \multicolumn{2}{|c|}{$\begin{array}{l}\text { Discontinuer } \\
(n=30)\end{array}$} \\
\hline & $n$ or $M$ & $\%$ or $S D$ & $n$ or $M$ & $\%$ or $S D$ & $n$ or $M$ & $\%$ or $S D$ \\
\hline Age & 35.23 & 8.65 & 35.15 & 9.82 & 35.3 & 7.62 \\
\hline \multicolumn{7}{|l|}{ Race $^{\mathrm{a}}$} \\
\hline White & 41 & $71.93 \%$ & 19 & $70.37 \%$ & 22 & $73.33 \%$ \\
\hline Native American or Alaska Native & 0 & $0.00 \%$ & 0 & $0.00 \%$ & 0 & $0.00 \%$ \\
\hline East Asian & 1 & $1.75 \%$ & 0 & $0.00 \%$ & 1 & $3.33 \%$ \\
\hline West Asian & 0 & $0.00 \%$ & 0 & $0.00 \%$ & 0 & $0.00 \%$ \\
\hline Black/African-American & 6 & $10.53 \%$ & 3 & $11.11 \%$ & 3 & $10.00 \%$ \\
\hline Native Hawaiian or other Pacific Islander & 1 & $1.75 \%$ & 1 & $3.70 \%$ & 0 & $0.00 \%$ \\
\hline Multiracial & 7 & $12.28 \%$ & 3 & $11.11 \%$ & 4 & $13.33 \%$ \\
\hline Other & 3 & $5.26 \%$ & 1 & $3.70 \%$ & 2 & $6.67 \%$ \\
\hline Latinx $(n=56)$ & 8 & $14.29 \%$ & 3 & $11.11 \%$ & 5 & $17.24 \%$ \\
\hline \multicolumn{7}{|l|}{ Income $(n=52)$} \\
\hline$<\$ 20,000$ & 9 & $17.31 \%$ & 5 & $20.83 \%$ & 4 & $14.29 \%$ \\
\hline$\$ 20,000-\$ 55,000$ & 9 & $17.31 \%$ & 6 & $25.00 \%$ & 3 & $10.71 \%$ \\
\hline$\$ 55,000-\$ 100,000$ & 15 & $28.85 \%$ & 5 & $20.83 \%$ & 10 & $35.71 \%$ \\
\hline$\$ 100,000+$ & 19 & $36.54 \%$ & 8 & $33.33 \%$ & 11 & $39.29 \%$ \\
\hline Don't know/prefer not to answer & 0 & $0.00 \%$ & & $0.00 \%$ & & $0.00 \%$ \\
\hline \multicolumn{7}{|l|}{ Education $(n=52)$} \\
\hline Less than BA & 5 & $9.62 \%$ & 2 & $8.33 \%$ & 3 & $10.71 \%$ \\
\hline $\mathrm{BA}$ & 20 & $38.46 \%$ & 6 & $25.00 \%$ & 14 & $50.00 \%$ \\
\hline More than BA & 26 & $50.00 \%$ & 15 & $62.50 \%$ & 11 & $39.29 \%$ \\
\hline Other & 1 & $1.92 \%$ & 1 & $4.17 \%$ & 0 & $0.00 \%$ \\
\hline \multicolumn{7}{|l|}{ Gender identity $(n=56)$} \\
\hline Man & 52 & $92.86 \%$ & 27 & $100.00 \%$ & 25 & $86.21 \%$ \\
\hline Woman & 1 & $1.79 \%$ & 0 & $0.00 \%$ & 1 & $3.45 \%$ \\
\hline Non-binary & 2 & $3.57 \%$ & 0 & $0.00 \%$ & 2 & $6.90 \%$ \\
\hline Another gender not listed & 1 & $1.79 \%$ & 0 & $0.00 \%$ & 1 & $3.45 \%$ \\
\hline Transgender $(n=56)$ & 7 & $12.50 \%$ & 3 & $11.11 \%$ & 4 & $13.79 \%$ \\
\hline \multicolumn{7}{|l|}{ Sexual orientation } \\
\hline Asexual & 0 & $0.00 \%$ & 0 & $0.00 \%$ & 0 & $0.00 \%$ \\
\hline Bisexual & 2 & $3.51 \%$ & 2 & $7.41 \%$ & 0 & $0.00 \%$ \\
\hline Gay or lesbian & 42 & $73.68 \%$ & 20 & $74.07 \%$ & 22 & $73.33 \%$ \\
\hline Heterosexual & 3 & $5.26 \%$ & 0 & $0.00 \%$ & 3 & $10.00 \%$ \\
\hline Pansexual & 1 & $1.75 \%$ & 1 & $3.70 \%$ & 0 & $0.00 \%$ \\
\hline Queer & 7 & $12.28 \%$ & 4 & $14.81 \%$ & 3 & $10.00 \%$ \\
\hline I'm not sure & 0 & $0.00 \%$ & 0 & $0.00 \%$ & 0 & $0.00 \%$ \\
\hline Another identity not listed & 2 & $3.51 \%$ & 0 & $0.00 \%$ & 2 & $6.67 \%$ \\
\hline \multicolumn{7}{|l|}{ Relationship status } \\
\hline Single & 31 & $54.39 \%$ & 13 & $48.15 \%$ & 18 & $60.00 \%$ \\
\hline One or more serious relationships & 19 & $33.33 \%$ & 9 & $33.33 \%$ & 10 & $33.33 \%$ \\
\hline Other & 7 & $12.28 \%$ & 5 & $18.52 \%$ & 2 & $6.67 \%$ \\
\hline \multicolumn{7}{|l|}{ Region $(n=56)$} \\
\hline West & 4 & $7.14 \%$ & 1 & $3.70 \%$ & 3 & $10.00 \%$ \\
\hline Midwest & 3 & $5.36 \%$ & 1 & $3.70 \%$ & 2 & $6.67 \%$ \\
\hline South & 25 & $44.64 \%$ & 13 & $48.15 \%$ & 12 & $40.00 \%$ \\
\hline Northeast & 23 & $41.07 \%$ & 11 & $40.74 \%$ & 12 & $40.00 \%$ \\
\hline Pacific & 1 & $1.79 \%$ & 1 & $3.70 \%$ & 0 & $0.00 \%$ \\
\hline
\end{tabular}


Table 4 (continued)

\begin{tabular}{|c|c|c|c|c|c|c|}
\hline & \multicolumn{2}{|c|}{ PrEP user $(n=57)$} & \multicolumn{2}{|c|}{ Continuer $(n=27)$} & \multicolumn{2}{|c|}{$\begin{array}{l}\text { Discontinuer } \\
(n=30)\end{array}$} \\
\hline & $n$ or $M$ & $\%$ or $S D$ & $n$ or $M$ & $\%$ or $S D$ & $n$ or $M$ & $\%$ or $S D$ \\
\hline \multicolumn{7}{|l|}{ Sexual behavior } \\
\hline Currently having sex with anyone outside of household/isolation pod & 17 & $29.82 \%$ & 14 & $51.85 \%$ & 3 & $10.00 \%$ \\
\hline Oral sex in the past 12 months & 56 & $98.25 \%$ & 27 & $100.00 \%$ & 29 & $96.67 \%$ \\
\hline Penetrative intercourse in the last 12 months & 54 & $94.74 \%$ & 27 & $100.00 \%$ & 27 & $90.00 \%$ \\
\hline Engaged in any partnered activity since the beginning of the pandemic & 37 & $64.91 \%$ & 21 & $77.78 \%$ & 16 & $53.33 \%$ \\
\hline Engaged in any partnered activity in the past two weeks & 27 & $47.37 \%$ & 18 & $66.67 \%$ & 9 & $30.00 \%$ \\
\hline Planning on engaging in partnered sexual activity in the next two weeks & 29 & $50.88 \%$ & 19 & $70.37 \%$ & 10 & $33.33 \%$ \\
\hline Number of sex partners last 3 months & 5.20 & 5.80 & 6.69 & 6.99 & 3.86 & 4.15 \\
\hline Number of times gave oral sex in past 30 days & 2.70 & 4.94 & 4.23 & 6.33 & 1.29 & 2.54 \\
\hline Number of times received oral sex in past 30 days & 3.09 & 6.00 & 4.19 & 6.13 & 2.1 & 5.8 \\
\hline Number of times had vaginal sex in past 30 days & 0.83 & 2.20 & 1 & 2.56 & 0.67 & 1.82 \\
\hline Number of times had anal sex in past 30 days & 3.63 & 7.42 & 5.35 & 8.3 & 1.92 & 6.1 \\
\hline Percentage of time used a condom during intercourse in past 30 days & 9.24 & 22.02 & 10 & 24.88 & 8.12 & 17.64 \\
\hline Likelihood of needing access to PrEP/PEP during lockdown & 4.69 & 2.40 & 6.04 & 1.64 & 3.48 & 2.36 \\
\hline Likelihood of needing access to contraceptives during lockdown & 1.38 & 1.38 & 1.44 & 1.53 & 1.32 & 1.25 \\
\hline $\begin{array}{l}\text { Likelihood of needing access to morning after pill/emergency contracep- } \\
\text { tion during lockdown }\end{array}$ & 1.17 & 0.92 & 1.24 & 1.2 & 1.11 & 0.58 \\
\hline
\end{tabular}

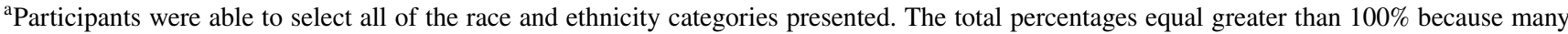
participants selected more than one category. ${ }^{\mathrm{b}}$ Likelihood of needing sexual healthcare services rated on a 7 -point Likert scale $(1=$ very unlikely, $7=$ very likely)

remote healthcare services for birth control, and increased vigilance over pregnancy prevention.

No or Low Pregnancy Risk Multiple participants agreed that their birth control decisions were affected by their current unintended pregnancy risk. Some cited temporary abstinence, including one participant who said, “... because I am not sexually active [birth control] is pointless." Other participants reported that their sexual activity did not put them at risk for pregnancy; one participant said they "have been sterilized since 1997" while another said, "I have an IUD and I only have sex with vaginas." These participants did not change their contraception decisions as a result of the pandemic because they were not concerned about unintended pregnancy.

Birth Control for Health Reasons Beyond Pregnancy Prevention Several participants who reported continued birth control said they used birth control for reasons unrelated to pregnancy prevention, including "period pain" and "to control/balance my hormones, which have caused health issues." Conversely, other participants cited decreased pregnancy risk during the pandemic as an opportunity to discontinue the pill for mental and physical health reasons.

Long-Acting Reversible Contraceptives Several other participants also reported using long-acting birth control methods.
Most indicated no change in their use of these long-acting methods such as IUDs and implants because, as one participant said, “...it doesn't depend on daily adherence decisions." However, two participants expressed concerns about needing their IUDs replaced. Said one participant, "My IUD has expired since quarantine. And I cannot get a new one during this time. Additionally, I cannot take other forms of birth control while my IUD is in me, but cannot get it removed either. My partner and I have been increasing in use of condoms."

Access to Remote Healthcare Services While birth control access was limited as a result of the pandemic, some participants had access to telehealth options. One participant said, "With my healthcare, I get my birth control pills delivered, so things will not change with the onset of the pandemic." Another participant reported starting birth control since the onset of the pandemic. They said, "I actually went on birth control in April 2020. I used planned parenthood's telehealth and the [Planned Parenthood Direct] app to order my [birth control]. I wanted an IUD to stop my period completely but I did not want to go to the clinic in person, so I'm using a pill instead." Compared to participants on PrEP, those on birth control were less reliant on in-person medical services to access medication.

Increased Vigilance over Pregnancy Prevention Like the participant who started birth control in April 2020, multiple 
participants expressed increased vigilance over pregnancy prevention. One individual stated, "I have ZERO desire to get pregnant and either seek an abortion or get prenatal care during a pandemic." Another participant shared a similar sentiment, saying,

"Originally had stopped taking medications until a couple of months ago until a friend recently got pregnant and had an abortion procedure done. I always use condoms but it still worried me so started back on Yaz and soon switching to Xulane patch."

This increased vigilance did not necessarily reflect changes in sexual behavior but rather changes in participants' motivation to avoid unintended pregnancy.

\section{What Reasons Do People Self-Report for their PrEP (Dis) continuation?}

Of the 57 PrEP users who were asked to provide qualitative descriptions of their PrEP use or discontinuation during the pandemic, $70.2 \%(n=40)$ responded. These respondents were not demographically different from participants who skipped the question. Among the qualitative responses about participant reasons for PrEP continuation and discontinuation $(n=40)$, four major themes emerged. The predominant reason participants gave for PrEP continuation was psychological well-being, and the predominant reasons participants gave for PrEP discontinuation were temporary abstinence and concerns about accessing inperson health care. Participants also wanted to remain prepared for post-pandemic sexual behavior, which motivated some to continue daily PrEP and led others to temporarily discontinue PrEP or switch to 2-1-1 event-driven PrEP use.

Psychological Well-Being Psychological well-being was a recurring theme among individuals who described a reason for PrEP continuation. Specifically, multiple participants indicated that their decision to continue PrEP was motivated by the sense of security that comes with biomedical HIV protection, including one participant with an HIV-positive sexual partner:

"I am slightly less strict about adherence because... the only person I've had sex with since early March is HIV-positive, reports having had a consistently undetectable viral load for several years, and I do believe he has an undetectable viral load and cannot transmit HIV to me. However, even though he's my only sexual partner, I'm continuing PrEP anyway for the anxiety / emotional benefit of not needing to depend on his medication adherence for my HIV prevention, even though I trust that he's adherent, and because whenever I do start having sex with other people, the CDC says it'll take 20 days of daily dosing for me to regain maximal protection, and I may struggle to wait that long, so I'd rather maintain maximal protection throughout the pandemic."

Temporary Abstinence Like the participants who cited temporary abstinence as their reason for discontinuing birth control, some PrEP users reported prior or upcoming PrEP discontinuation due to changes in their sexual behavior during the pandemic. Some participants indicated they were abstinent at the time of the survey, including one participant who said they "....stopped taking PrEP while abstaining from sex." However, abstinence had not led all participants to discontinue, including one who said, "I still continue taking it even though I haven't had sex." Other participants expressed that they had been abstinent at the beginning of the pandemic, but had taken steps to resume sexual activity. One participant referenced "loosening" lockdown restrictions while another cited mental health concerns, saying, "I stopped [PrEP] for a month but started taking it again after I decided living alone, working alone, and abstinence was damaging my mental health."

Remaining Prepared for Post-Pandemic Other participants similarly indicated a desire to be prepared for post-pandemic sexual behavior. This was a reason cited for both participants continuing daily PrEP and individuals temporarily discontinuing PrEP. One participant wrote, "While I don't feel I really need [PrEP] for protection at the moment, I don't want to loose ( sic) the habit, and I want to be ready for the post-covid era." While this individual prepared for future PrEP need by continuing to take daily PrEP, others reported preparing for future need by saving their current supply or switching to 2-1-1 use. One participant said they "... stopped taking it to stockpile" and another said, "...If I were to obtain a refill, I would save any newly acquired PrEP medication for 2-1-1 use, in the unlikely event I would be having sex." Two other participants also reported shifts from daily PrEP to 2-1-1 event-driven PrEP.

Concerns about Accessing In-Person Health Care Related to concerns about PrEP supply were concerns about accessing in-person health care. Said one participant, "My medication has run out and I do not feel comfortable going out to pick up a refill." Another reported, "I am more worried about going in person for bloodwork than continuing prep while in quarantine, so if I have to go physically to the lab for bloodwork, then I will probably opt to go off the medication and resume when it feels safe to go in person to the dr." PrEP users had access to fewer telehealth options than those seeking birth control. 


\section{Discussion}

In the present study, we examined patterns of continuation and discontinuation of birth control and PrEP during the COVID19 pandemic. The majority of people who used birth control before the pandemic continued to do so. Participants reported several factors related to continuation, including birth control use for health reasons beyond pregnancy prevention, long-term use options (i.e., LARCs), and increased vigilance over pregnancy prevention during the pandemic. Comparatively, approximately half of PrEP users reported discontinuation for reasons related to the pandemic. PrEP users who discontinued PrEP commonly reported temporary abstinence due to the pandemic, a desire to save PrEP pills for use post-pandemic, or concerns about attending in-person health care to continue PrEP use. Continuing PrEP users reported wanting to maintain the positive psychological benefits of PrEP or wanting to keep up the habit.

These exploratory findings suggested preliminary patterns in the use of two important aspects of preventative sexual health care: birth control and PrEP. The discontinuation patterns in the present study demonstrated key differences in how our healthcare system engages patients in birth control use and PrEP use. Firstly, birth control is used to treat many medical needs beyond pregnancy prevention, whereas the main use of PrEP is HIV prevention. Many birth control users continued birth control even when abstinent, citing health reasons. Secondly, birth control users reported either using LARCs or having access to telemedicine or prescription delivery to continue birth control. In contrast, several PrEP users reported challenges accessing health care. While it is considered best medical practice for PrEP users to receive quarterly STI testing (Centers for Disease Control \& Prevention, 2017), requiring frequent interaction with the healthcare system may be one barrier to sustained PrEP use, especially in the context of a global pandemic.

PrEP users may also face more cultural stigma than birth control users at both the institutional and interpersonal levels. In previous studies, cisgender men who have sex with men (MSM) and transgender women who have sex with men have reported anticipating or experiencing PrEP-related stigma from both providers and potential sexual partners (Matacotta et al., 2020; Schwartz \& Grimm, 2016). Individuals in these groups, who may already experience HIV stigma in the form of assumptions about their sexual behavior and HIV risk (Earnshaw \& Chaudoir, 2009), feared experiencing additional stigma if they used PrEP. PrEP stigma in the healthcare system contributes to both limitations on PrEP access options (e.g., monitoring requirements, low telehealth availability) and anticipated stigma for those seeking PrEP care, making it harder for individuals to continue and manage PrEP treatment.

Individuals' decisions about birth control versus PrEP continuation may have also been due to their own assumptions about the potential outcomes of their sexual behavior. As previously stated, HIV risk is assumed to increase with the number of sexual partners (Centers for Disease Control \& Prevention, 2017), while pregnancy risk increases with each instance of intercourse, regardless of the number of unique partners. More than twothirds of birth control users reported engaging in sexual activity since the beginning of the pandemic, and nearly as many intended to do so in the next two weeks. However, only a small subset of birth control users reported having sex with anyone outside their household/lockdown pod (12.5\%). This suggests that birth control users who were sexually active during the first months of the COVID-19 pandemic were predominately having sex with relationship partners in their household. It is likely that few participants discontinued birth control use in response to the pandemic because the primary source of their unintended pregnancy risk remained unchanged. Similarly, PrEP users may have made decisions about continuation or discontinuation in response to their understanding of their own sexual behavior. Among those who reported having sex with someone outside of their household or isolation pod, the vast majority indicated intentions to remain on PrEP. Conversely, among those who were not having sex with anyone outside of their household, more than two-thirds discontinued PrEP or expressed intentions to do so. This suggests that participants may have made decisions about PrEP continuation in accordance with their expectation of having new sexual partners during the pandemic.

Another consideration for understanding PrEP and birth control use during COVID-19 is the difference in availability of long-acting options. Many of the birth control users in our sample used long-acting birth control methods, which facilitated birth control continuation for some and posed particular issues for others, such as those who needed to get their IUDs removed but were unable to access in-person health care due to the pandemic. Health information about the safety and efficacy of LARCs such as the IUD should be available to support birth control users who find themselves in this precarious position. Efforts to make sexual health care available should also consider this need as there may be certain clinicians who specialize in IUD insertion and removal (Harper et al., 2012). The findings regarding long-acting birth control have implications for future PrEP use, as the safety and efficacy of long-acting injectable PrEP are currently being evaluated in clinical trials (Tolley et al., 2020). Because long-acting PrEP will be administered in a shot and does not require removal, long-acting PrEP has the potential to increase PrEP continuation in general and especially in situations when there are additional strains on the healthcare system, such as during the COVID19 pandemic or in rural areas with lesser healthcare resources (Laditka et al., 2009).

A few participants reported saving their PrEP medication for event-driven 2-1-1 dosing. This is notable because event-driven PrEP is more appealing to individuals who can anticipate sexual encounters (Reyniers et al., 2018) which may be more likely during the COVID-19 pandemic, as individuals may be making more intentional decisions about close contact. Despite this, 
there is currently little health education about event-driven PrEP (e.g., Saberi \& Scott, 2020). Increasing awareness about effective event-driven PrEP use may facilitate successful biomedical HIV prevention, especially in circumstances where preventative sexual health care is especially limited.

Regarding birth control, several participants reported increased vigilance around pregnancy prevention. In other words, COVID-19 has made pregnancy especially undesirable for some people. This is likely due to the additional financial, health-related, and isolation-related challenges that would make pregnancy and child-rearing particularly difficult (Dib et al., 2020; Salehi et al., 2020). We did not see this pattern with PrEP use. Individuals did not express increased vigilance over HIV prevention. This may be related to decreased sexual behavior associated with discontinuation; however, it may also be that HIV and other illnesses may become less salient in a climate where COVID-19 risk is centered in public health discourse (Stephenson et al., 2020).

In all, our findings point to the benefits of telemedicine and prescription accessibility for facilitating preventative sexual health care and that these benefits have not been extended to PrEP to the same extent as birth control. The availability and use patterns of hormonal birth control and PrEP in the present study reflect larger cultural norms of prioritizing preventing unintended pregnancy over sexually transmitted infections (World Health Organization [WHO], 2017), particularly among single women, and controlling the sexual behavior of populations stereotyped as sexually promiscuous, such as sexual minority men (Pinsof \& Haselton, 2017). Especially during the healthcare disruptions of the COVID-19 pandemic, it is crucial to increase remote accessibility of sexual health services and reduce the stigma associated with their use.

\section{Strengths and Limitations}

There are several strengths and limitations to the present investigation. One strength is that this adds to the limited research on PrEP and birth control use during COVID-19. Additionally, this work has implications that extend beyond the time of the COVID19 pandemic and serve as a case study for thinking about barriers and facilitators to PrEP and birth control as preventative sexual health care. Utilizing a mixed-methods approach was informative for understanding self-reported reasons for continuation and discontinuation. This approach allowed for the examination of general trends, as well as specific factors that affect decision making.

There are several limitations as well. First, this was an exploratory investigation of patterns of birth control and PrEP use using an online convenience sample. Secondly, the sample sizes of birth control discontinuers and PrEP users were too small for inferential analyses. While the trends discussed are informative for understanding use patterns, future studies should involve larger, more representative samples and more complex statistical analyses.
There are also limitations with some measures included in the study. As previously stated, participants were asked, "Are you currently using contraception/birth control methods other than condoms (i.e., birth control pills, IUD, etc.)?" The question did not specify contraception methods beyond those provided as examples, and it was up to the interpretation of the participant what exactly fell under the umbrella of "contraception" or "birth control." The survey contained display logic, such that only participants who indicated using contraception/birth control were asked to select their birth control method from a provided list created by the research team. The list included IUDs, hormonal pills, injections, implants, and IUDs and hormonal pills together. These options are only a limited set of possible contraception or birth control options that participants could have been using, and did not allow participants to indicate a method other than those listed. However, $97.1 \%$ reported using one of the methods listed. While it is possible that those using either permanent (e.g., tubal sterilization, vasectomy) or less common birth control methods (e.g., vaginal rings) were not included in the sample of birth control users, this does not appear to be the case. Four participants self-identified as birth control users but skipped the following question about their birth control method; two of these participants later described the use of permanent methods, suggesting that those who used methods other than the ones listed likely responded affirmatively to the question about birth control use and then skipped the following question. Still, future research should more explicitly and comprehensively define the category of "birth control users."

Further, although we did collect information demonstrating that most participants were experiencing some type of lockdown policy in their area of residence, we did not ask specifically about whether healthcare facilities were open and available. Thus, we cannot know for certain if those who reported continuing their birth control or PrEP use did so due to easier access (e.g., doctor's offices still open at the time of survey completion) or due to their own motivations. While the qualitative results speak to some of these reasons, the present study does not fully contextualize each respondent's access in relation to pandemic constraints in one particular place and time.

Another limitation is the discrepancy between the measures of birth control use and continuation and the measures of PrEP use and continuation. Both birth control users and PrEP users were asked, "Do you have plans to discontinue your prescription during lockdown?" For both user groups, those who said they had plans to discontinue were categorized as discontinuers. However, for PrEP only, participants were also asked whether they had already discontinued use during the pandemic, prior to the time of the survey. Thus, for the comparison of PrEP users and nonusers, PrEP discontinuers were people who either indicated that they had already stopped PrEP due to the pandemic or indicated plans to discontinue soon. For the comparison of birth control users and nonusers, birth control discontinuers were only those who indicated plans to discontinue soon. The omission 
of the question regarding previous discontinuation among birth control users during the pandemic but prior to the time of the survey was an error on the part of the research team. As such, we cannot know the percentage of our sample who had been on birth control before but had already discontinued due to the pandemic. The pandemic began in the USA around March 2020, and we defined it for participants as such. The data collection period ranged from April 2020 to June 2020. Thus, this leaves up to three months unaccounted for. The majority of birth control users in our sample (91.2\%) did indicate continuing their birth control use, and a review of the qualitative responses indicated that only one birth control continuer had discontinued and reinitiated birth control before the time of the survey. Thus, despite this difference in measurement, it is unlikely that a sizeable number of those categorized as birth control users would have discontinued their birth control use due to the pandemic within that small window of time prior to the survey. That said, any future research should certainly strive to capture discontinuation throughout the pandemic.

Further, because the question for PrEP users was worded as whether or not they, "stopped due to lockdown orders," it is possible that individuals who stopped for other reasons (e.g., something that decreased their risk level, like the beginning or end of a relationship), may not have indicated discontinuation in response to this question. Future research should examine these continuation and discontinuation patterns in more depth, including how they were affected by specific aspects of pandemic health policy.

Although we examined similarities and differences between continuation patterns and use of these two preventative medications, it is important to keep in mind that the groups utilizing PrEP and birth control are demographically different. The individuals on birth control in our sample were primarily cisgender women, while the individuals using PrEP were primarily sexual minority men, consistent with overall use trends (Rodriguez et al., 2020; Centers for Disease Control \& Prevention, 2019). Existing research suggests that women, in general, have higher rates of healthcare utilization (Pinkhasov et al., 2010) and gender socialization may play a role in the differences in utilization of these medications. Further, four individuals in our sample reported concurrent birth control and PrEP use. These four individuals were white transgender men in their 20 s who identified as either gay or queer and utilized LARCs (i.e., either IUD or implant). While not examined in depth in the present study, future research should address patterns of simultaneous PrEP and birth control use, with consideration of provider prescribing behaviors that may target or leave out populations that could benefit from access to this combination of services.

Notably, $10 \%(n=13)$ of birth control users and 13\% $(n=7)$ of the PrEP users in the present study identified as transgender. Due to the sample sizes of the birth control and PrEP continuers and discontinuers, we were unable to examine meaningful differences between cisgender and transgender participants. However, existing research suggests that transgender individuals may face particular barriers when accessing birth control (Harb et al.,
2019) and PrEP (Sevelius et al., 2016), contingent upon systemic inequities. It is imperative that future researchers strive to capture the needs and experiences of transgender individuals to lessen barriers to health care.

Additionally, the evaluation of sexual behavior in the present study is limited in that we did not examine survival sex or sex work, which was likely heavily impacted during the pandemic (Platt et al., 2020). With half of the PrEP continuers in our research sample $(n=14,51.9 \%)$ having reported sex with someone outside of their household/lockdown pod, there was no opportunity for clarification as to if such sex outside of their pod was required for income or other means of survival during the pandemic (i.e., survival sex, sex in exchange for money, or sex work). In bringing up this limitation of the study, we hope to acknowledge that there are individuals whose sexual experiences are not fully contextualized, especially considering the increase of survival sex and sex work caused by financial challenges during the pandemic (Platt et al., 2020).

\section{Future Research Directions}

There are many future directions researchers should explore related to birth control and PrEP use during and after the COVID19 pandemic. First, considering our sample was predominately white, future research should focus specifically on access to preventative sexual health care among communities of color during the COVID-19 pandemic. This is especially important considering the ongoing impact of systemic racism on both sexual health (Millett et al., 2020; Prather et al., 2016) and COVID-19 outcomes (e.g., Gravlee, 2020). In addition, as mentioned above, more attention to the specific needs and challenges of transgender and gender expansive individuals during the COVID-19 pandemic is warranted, both in relation to sexual health care and all other aspects of care.

In addition, many participant responses discussed abstinence; therefore, it is important to continue to examine how sexual behavior patterns relating to birth control and PrEP use change over the course of the pandemic. This is especially important as there will likely be regions around the world engaging in COVID-19 precautions for a long time, and it is unclear how people will behave in times of prolonged viral threat. Will individuals return to engaging in higher levels of sexual behavior, even when COVID-19 is still an imminent risk? How will these behavioral shifts contribute to preventative sexual healthcare needs? Researchers should also examine patterns of re-uptake of PrEP among individuals who stopped use during the pandemic. Is it harder for individuals who have discontinued to then re-uptake PrEP and maintain adherence when sexual health care becomes more accessible? Have PrEP discontinuers made plans to restart PrEP? Further, how has COVID-19 influenced attitudes toward HIV prevention and pregnancy overall? A recent study demonstrated that gay and bisexual men engaged in more precautionary behavior than did heterosexual men in response to 
the COVID-19 pandemic (Price, Gesselman, et al., 2020). The researchers proposed that as gay and bisexual men have been the target of HIV-reduction campaigns for decades, these men likely better understand why precautionary behavior is necessary and beneficial. As the COVID-19 pandemic further centers conversations on contagion, self-protection, and consideration of the well-being of others, we may see changing cognitions around HIV and HIV prevention. Our own results suggest an increased vigilance over pregnancy prevention among birth control users, but research directly examining these patterns over time will contribute to a more complete understanding of reasons for engagement in — and barriers to - preventative sexual health care.

Additionally, future research should examine the structuraland policy-related factors that impact sexual health care during the pandemic. How do different COVID-19 safety policies and healthcare structures impact preventative sexual health care differently? Are there contexts we can look to as a model for accessible sexual health care during the pandemic, and how can we have procedures in place in the case of future challenges? Understanding the systems themselves is important for understanding the contexts in which people are making decisions about birth control and PrEP use.

This research on birth control and PrEP use in the context of the COVID-19 pandemic is ongoing. We are currently administering a follow-up survey to examine how participants' sexual behavior and utilization of sexual healthcare services changed over the first year of the COVID-19 pandemic. We thereby hope to address many of the questions posed by the current study. Additionally, we will explore how state-level lockdown policies and rates of COVID-19 transmission impacted preventative sexual healthcare access and utilization. At the time of the initial survey creation, it was not yet clear how COVID-19 rates and related restrictions would fluctuate in the subsequent months, and to what extent these patterns would be region-specific. By asking participants follow-up questions about their local environment, we will be able to further contextualize their experiences with preventative sexual health care in the context of the COVID-19 pandemic.

\section{Conclusion}

In the USA, the COVID-19 pandemic has created challenges for many domains within the healthcare sector, including preventative sexual health care. If access to, and continuation of, preventative sexual health care — such as birth control or PrEP use - has been interrupted or threatened due to the COVID-19 pandemic, we may observe those negative effects at the national level for years to come (e.g., higher rates of unintended pregnancies and new cases of HIV). In this study, most participants reported continuation of their hormonal birth control along with increased vigilance over pregnancy prevention. Conversely, around half of PrEP-using participants reported already discontinuing or planning to discontinue their PrEP regimen. Many cited current abstinence and desire to "stockpile" for a time when they will be sexually active again. Both of these patterns of findings have implications for future research and intervention design.

Acknowledgements We would like to acknowledge Dr. Sarit A. Golub for funding this project with her Hunter College faculty funds and her support and guidance on this project.

Funding This project was supported by Dr. Sarit Golub's faculty funds.

Availability of Data and Material Data and material for the present study are not currently publicly available, but will be made available upon reasonable request. Please contact the corresponding author with datarelated questions.

Code availability Not available.

\section{Declarations}

Conflict of interest The authors of this manuscript declare no conflicts of interest or competing interests.

\section{References}

Allen, A., Fikslin, R. A., Unger, Z., \& Golub, S. A. (2020). Beyond behavior: Examining positive psychological factors and traditional risk perception in PrEP decision-making. [Manuscript submitted for publication].

American Hospital Association. (2020). Hospitals and health systems face unprecedented financial pressures due to COVID-19. https:// www.aha.org/guidesreports/2020-05-05-hospitals-and-healthsystems-face-unprecedented-financial-pressures-due

Barry, C. L., Han, H., Presskreischer, R., Anderson, K. E., \& McGinty, E. E. (2020). Public support for social safety-net policies for COVID-19 in the United States, April 2020. American Journal of Public Health, 110(12), 1811-1813. https://doi.org/10.2105/ AJPH.2020.305919

Braun, V., \& Clarke, V. (2006). Using thematic analysis in psychology. Qualitative Research in Psychology, 3(2), 77-101. https://doi.org/ 10.1191/1478088706qp063oa

Carlo Hojilla, J., Koester, K. A., Cohen, S. E., Buchbinder, S., Ladzekpo, D., Matheson, T., \& Liu, A. Y. (2016). Sexual behavior, risk compensation, and HIV prevention strategies among participants in the San Francisco PrEP demonstration project: A qualitative analysis of counseling notes. AIDS and Behavior, 20(7), 14611469. https://doi.org/10.1007/s10461-015-1055-5

Centers for Disease Control and Prevention. (2017). Pre-exposure prophylaxis for the prevention of HIV infection in the United States: A clinical practice guideline. U.S. Public Health Service. https://www.cdc.gov/hiv/pdf/risk/prep/cdc-hiv-prep-guidelines2017.pdf

Centers for Disease Control and Prevention. (2019). Key Statistics from the National Survey of Family Growth. National Center for Health Statistics. https://www.cdc.gov/nchs/nsfg/key_statistics_ 2015_2017.htm

Chappell, B. (2020, March 11). Coronavirus: COVID-19 is now officially a pandemic, WHO says. NPR. https://www.npr.org/sections/ 
goatsandsoda/2020/03/11/814474930/coronavirus-covid-19-isnow-officially-a-pandemic-who-says

Dib, S., Rougeaux, E., Vázquez-Vázquez, A., Wells, J. C. K., \& Fewtrell, M. (2020). Maternal mental health and coping during the COVID19 lockdown in the UK: Data from the COVID-19 New Mum Study. International Journal of Gynecology \& Obstetrics, 151(3), 407-414. https://doi.org/10.1002/ijgo.13397

Dubov, A., Galbo, P., Jr., Altice, F. L., \& Fraenkel, L. (2018). Stigma and shame experiences by MSM who take PrEP for HIV prevention: A qualitative study. American Journal of Men's Health, 12(6), 1843-1854. https://doi.org/10.1177/1557988318797437

Earnshaw, V. A., \& Chaudoir, S. R. (2009). From conceptualizing to measuring HIV stigma: A review of HIV stigma mechanism measures. AIDS and Behavior, 13(6), 1160-1177. https://doi.org/10. 1007/s10461-009-9593-3

Elion, R. A., Kabiri, M., Mayer, K. H., Wohl, D. A., Cohen, J., Beaubrun, A. C., \& Altice, F. L. (2019). Estimated impact of targeted pre-exposure prophylaxis: Strategies for men who have sex with men in the United States. International Journal of Environmental Research and Public Health, 16(9), 1592-1606. https://doi.org/ 10.3390/ijerph16091592

Fernandes, D. E., Ferreira, P. R. A., \& Kirsztajn, G. M. (2020). Preexposure prophylaxis during the SARS-CoV-2 pandemic: can PrEP prevent COVID-19-related symptoms? Epidemiology \& Infection, 148, e231. https://doi.org/10.1017/S0950268820002253

Food and Drug Administration. (2014). Truvada for PrEP fact sheet: Ensuring safe and proper use. https://www.fda.gov/media/83586/ download

Golub, S. A., Fikslin, R. A., Goldberg, M. H., Peña, S. M., \& Radix, A. (2019). Predictors of PrEP uptake among patients with equivalent access. AIDS and Behavior, 23(7), 1917-1924. https://doi.org/10. 1007/s10461-018-2376-y

Grandi, G., Barra, F., Ferrero, S., Sileo, F. G., Bertucci, E., Napolitano, A., \& Facchinetti, F. (2019). Hormonal contraception in women with endometriosis: A systematic review. The European Journal of Contraception \& Reproductive Health Care, 24(1), 61-70. https:// doi.org/10.1080/13625187.2018.1550576

Gravlee, C. C. (2020). Systemic racism, chronic health inequities, and COVID-19: A syndemic in the making? American Journal of Human Biology, 32(5), e23482. https://doi.org/10.1002/ajhb. 23482

Guttmacher Institute. (2020). Contraceptive use in the United States. https://www.guttmacher.org/fact-sheet/contracept ive-use-united-states

Harb, C. Y., Pass, L. E., De Soriano, I. C., Zwick, A., \& Gilbert, P. A. (2019). Motivators and barriers to accessing sexual health care services for transgender/genderqueer individuals assigned female sex at birth. Transgender Health, 4(1), 58-67. https://doi.org/10. $1089 /$ trgh. 2018.0022

Harper, C. C., Henderson, J. T., Raine, T. R., Goodman, S., Darney, P. D., Thompson, K. M., Dehlendorf, C., \& Speidel, J. J. (2012). Evidence-based IUD practice: Family physicians and obstetriciangynecologists. Family Medicine, 44(9), 637-645.

Kanj, R. V., Conard, L. A. E., Corathers, S. D., \& Trotman, G. E. (2019). Hormonal contraceptive choices in a clinic-based series of transgender adolescents and young adults. International Journal of Transgenderism, 20(4), 413-420. https://doi.org/10.1080/15532 739.2019.1631929

Kavanaugh, M. L., \& Jerman, J. (2018). Contraceptive method use in the United States: Trends and characteristics between 2008, 2012 and 2014. Contraception (stoneham), 97(1), 14-21. https://doi. org/10.1016/j.contraception.2017.10.003

Laditka, J. N., Laditka, S. B., \& Probst, J. C. (2009). Health care access in rural areas: Evidence that hospitalization for ambulatory caresensitive conditions in the United States may increase with the level of rurality. Health \& Place, 15(3), 761-770. https://doi.org/ 10.1016/j.healthplace.2008.12.007

Lehmiller, J. J., Garcia, J. R., Gesselman, A. N., \& Mark, K. P. (2021). Less sex, but more sexual diversity: Changes in sexual behavior during the COVID-19 Coronavirus pandemic. Leisure Sciences, 43(1-2), 295-304. https://doi.org/10.1080/01490400.2020.17740 16

Lete, I., \& Lapuente, O. (2016). Contraceptive options for women with premenstrual dysphoric disorder: Current insights and a narrative review. Open Access Journal of Contraception, 7, 117-125. https:// doi.org/10.2147/oajc.s97013

Lin, H., \& Lee, H. (2015). Utilization of and adherence to oral contraceptive pills and associated disparities in the United States: A baseline assessment for the impact of the Affordable Care Act of 2010. International Journal of Health Services, 45(4), 729-742. https://doi.org/10.1177/0020731415591244

Matacotta, J. J., Rosales-Perez, F. J., \& Carrillo, C. M. (2020). HIV preexposure prophylaxis and treatment as prevention-Beliefs and access barriers in men who have sex with men (MSM) and transgender women: A Systematic Review. Journal of PatientCentered Research and Reviews, 7(3), 265-274. https://doi.org/ 10.17294/2330-0698.1737

Mendoza, N., Tommaso, S., \& Genazzani, A. D. (2014). Hormonal contraceptive choice for women with PCOS: A systematic review of randomized trials and observational studies. Gynecological Endocrinology, 30(12), 850-860. https://doi.org/10.3109/09513 590.2014.943725

Millett, G. A., Honermann, B., Jones, A., Lankiewicz, E., Sherwood, J., Blumenthal, S., \& Sayas, A. (2020). White counties stand apart: The primacy of residential segregation in COVID-19 and HIV Diagnoses. AIDS Patient Care and STDs, 34(10), 417-424. https:// doi.org/10.1089/apc.2020.0155

Mosher, W. D., \& Jones, J. (2010). Use of contraception in the United States: 1982-2008. Vital Health Statistics, 23(29), 1-44.

Ornstein, C. (2020, June 15). How America's hospitals survived the first wave of the coronavirus. ProPublica. https://www.propublica. org/article/how-americas-hospitals-survived-the-first-wave-ofthe-coronavirus

Pampati, S., Emrick, K., Siegler, A. J., \& Jones, J. (2020). Changes in sexual behavior, PrEP adherence, and access to sexual health services due to the COVID-19 pandemic among a cohort of PrEPusing MSM in the South. medRxiv. https://doi.org/10.1101/2020. 11.09.20228494

Patel, R. R., Mena, L., Nunn, A., McBride, T., Harrison, L. C., Oldenburg, C. E., Liu, J., Mayer, K. H., \& Chan, P. A. (2017). Impact of insurance coverage on utilization of pre-exposure prophylaxis for HIV prevention. PLOS ONE, 12(5), e0178737. https://doi.org/10. 1371/journal.pone.0178737

Pebody, R. (2018). 380,000 people on PrEP globally, mostly in the USA and Africa. AIDSmap. https://www.aidsmap.com/news/oct-2018/ 380000-people-prep-globally-mostly-usa-and-africa-updated

Pinkhasov, R. M., Wong, J., Kashanian, J., Lee, M., Samadi, D. B., Pinkhasov, M. M., \& Shabsigh, R. (2010). Are men shortchanged on health? Perspective on health care utilization and health risk behavior in men and women in the United States. International Journal of Clinical Practice, 64(4), 475-487. https://doi.org/10. 1111/j.1742-1241.2009.02290.x

Pinsof, D., \& Haselton, M. G. (2017). The effect of the promiscuity stereotype on opposition to gay rights. PLOS ONE, 12(7), e0178534. https://doi.org/10.1371/journal.pone.0178534

Platt, L., Elmes, J., Stevenson, L., Holt, V., Rolles, S., \& Stuart, R. (2020). Sex workers must not be forgotten in the COVID-19 response. The Lancet, 396(10243), 9-11.

Prather, C., Fuller, T. R., Marshall, K. J., \& Jeffries, W. L., IV. (2016). The impact of racism on the sexual and reproductive health of 
African American women. Journal of Women's Health, 25(7), 664-671. https://doi.org/10.1089/jwh.2015.5637

Price, D. M., English, D., \& Golub, S. A. (2020). Parallel reductions in anxiety and HIV-related worry among pre-exposure prophylaxis (PrEP) users over time. [Manuscript submitted for publication].

Price, D. M., Gesselman, A. N., Fikslin, R. A., Goldberg, A. J., Pervez, O., Reinka, M. A., \& Franklin, E. (2020). How will I get COVID?: Understanding differences in heterosexual and sexual minority men's risk perception. [Manuscript submitted for publication].

Reyniers, T., Nöstlinger, C., Laga, M., De Baetselier, I., Crucitti, T., Wouters, K., Smekens, B., Buyze, J., \& Vuylsteke, B. (2018). Choosing between daily and event-driven pre-exposure prophylaxis: Results of a Belgian PrEP demonstration project. JAIDS Journal of Acquired Immune Deficiency Syndromes, 79(2), 186194. https://doi.org/10.1097/QAI.0000000000001791

Rodriguez, K., Kelvin, E. A., Grov, C., Meyers, K., Nash, D., \& Wyka, K. (2020). Exploration of the complex relationships among multilevel predictors of PrEP use among men who have sex with men in the United States. AIDS and Behavior. https://doi.org/10.1007/ s10461-020-03039-1

Saberi, P., \& Scott, H. M. (2020). On-demand oral pre-exposure prophylaxis with tenofovir/emtricitabine: What every clinician needs to know. Journal of General Internal Medicine, 35(4), 1285-1288. https://doi.org/10.1007/s11606-020-05651-2

Salehi, L., Rahimzadeh, M., Molaei, E., Zaheri, H., \& EsmaelzadehSaeieh, S. (2020). The relationship among fear and anxiety of COVID-19, pregnancy experience, and mental health disorder in pregnant women: A structural equation model. Brain and Behavior, 10(11), 1-8. https://doi.org/10.1002/brb3.1835

Schwartz, J., \& Grimm, J. (2016). PrEP on Twitter: Information, barriers, and stigma. Health Communication, 32(4), 509-516. https:// doi.org/10.1080/10410236.2016.1140271

Sevelius, J. M., Keatley, J., Calma, N., \& Arnold, E. (2016). 'I am not a man': Trans-specific barriers and facilitators to PrEP acceptability among transgender women. Global Public Health, 11(7-8), 1060-1075. https://doi.org/10.1080/17441692.2016.1154085

Siegler, A. J., Mayer, K. H., Liu, A. Y., Patel, R. R., Ahlschlager, L. M., Kraft, C. S., Fish, R., Wiatrek, S. E., \& Sullivan, P. S. (2019).
Developing and assessing the feasibility of a home-based preexposure prophylaxis monitoring and support program. Clinical Infectious Diseases, 68(3), 501-504. https://doi.org/10.1093/cid/ciy529

Stephenson, R., Chavanduka, T. M., Rosso, M. T., Sullivan, S. P., Pitter, R. A., Hunter, A. S., \& Rogers, E. (2020). Sex in the time of COVID-19: Results of an online survey of gay, bisexual and other men who have sex with men's experience of sex and HIV prevention during the US COVID-19 epidemic. AIDS and Behavior, 25, 40-48. https://doi.org/10.1007/s10461-020-03024-8

Tolley, E. E., Zangeneh, S. Z., Chau, G., Eron, J., Grinsztejn, B., Humphries, H., Liu, A., Siegel, M., Bertha, M., Panchia, R., Li, S., Cottle, L., Rinehart, A., Margolis, D., Jennings, A., Mccauley, M., \& Landovitz, R. J. (2020). Acceptability of long-acting injectable cabotegravir (CAB LA) in HIV-uninfected individuals: HPTN 077. AIDS and Behavior, 24, 2520-2531. https://doi.org/10.1007/ s10461-020-02808-2

Whitfield, T. H., Jones, S. S., Wachman, M., Grov, C., Parsons, J. T., \& Rendina, H. J. (2019). The impact of pre-exposure prophylaxis (PrEP) use on sexual anxiety, satisfaction, and esteem among gay and bisexual men. The Journal of Sex Research, 56(9), 1128-1135. https://doi.org/10.1080/00224499.2019.1572064

World Health Organization. (2017). Sexual health and its linkages to reproductive health: an operational approach. https://www.who. int/reproductivehealth/publications/sexual_health/sh-linkages-rh/ en/

Zuniga, C., Grossman, D., Harrell, S., Blanchard, K., \& Grindlay, K. (2019). Breaking down barriers to birth control access: An assessment of online platforms prescribing birth control in the USA. Journal of Telemedicine and Telecare, 26(6), 322-331. https:// doi.org/10.1177/1357633x18824828

Publisher's Note Springer Nature remains neutral with regard to jurisdictional claims in published maps and institutional affiliations. 